\title{
A smart city is a safe city: the current status of street crime and its victim prevention using a digital application
}

\author{
Y.V. Truntsevsky ${ }^{1}$, I.I. Lukiny ${ }^{1,3}$, A.V. Sumachev ${ }^{1}$, A.V. Kopytova ${ }^{2, *}$ \\ ${ }^{1}$ Ugra State University, Chekhov str., 16, Khanty-Mansiysk, 628012, Russia \\ 2 Tyumen Industrial University, Volodarskogo str., 38, Tyumen, 625000, Russia \\ ${ }^{3}$ Open Joint Stock Company "Russian Railways", Russia
}

\begin{abstract}
Modern street crime has been increasingly affecting the formation of the criminogenic situation in Russia. The main goal of this paper is exploring the possible application of modern digital technologies in the evaluation and prevention of public crime. The methods presented in this empirical research are: monitoring, statistical methods, modeling and questioning, content analysis, research result processing. As a result of the analysis of the received data, generalized quantitative and qualitative indicators of modern street crime were presented: prevalence of mercenary and violent crimes $(61,4 \%)$ in the current criminal situation in the city streets (structure of street crime); the percentage of street crime in relation to all crime done in public places is $45,0 \%$ with the rising tendency of serious crime and latency; places where street crime takes place are empty, open city spaces composing about $12 \%$ of all the streets of the city; the prevailing "work schedule" of a street criminal is determined by the time of the year (fallwinter); day of the week (Friday, weekends and holidays) and time of day (evening-night); the increase in mobile phone theft from people passing in the streets; a characteristic way of street theft and robbery is their suddenness and unpredictability. The article supports the conclusion that the current system of street crime prevention methods and its practice doesn't provide salvation from street criminals and thus requires further improvement with the consideration of the rising possibilities of the internet-space, specifically, usage of digital applications and devices.
\end{abstract}

\section{Introduction}

One of the manifestations of crime, actively progressing in the current conditions, are crimes, held in public places and streets.

Street crime - is one of the most relevant problems of every big region of Russia. Most crimes take place in highly populated cities, a big part of which are offenses done outside and in public places.

\footnotetext{
*Corresponding author: a.copytowa@yandex.ru
} 
It is easier to prepare and hide and crime in a city than in the countryside, there is also a higher chance to use the profits from the crime. Moreover, a big part of street crime is latent. Modern street crime has a growing influence on the formation of the criminogenic situation in Russia: about $12 \%$ of all registered crime takes place in the street; every 7 th serious and particularly serious offense; every 2 nd robbery; every 3 rd criminal attack or criminally punishable hooliganism [1-4].

Prevention of street crime is currently seen as the most important reserve to lowering crime rates in general, and an effective law enforcement activity in this direction - as a necessary condition of the decline in the criminal tension in the city streets and populated areas. In the recent years a vast complex of measures has been taken, which is aimed at the development of a government structure that would meet the time criteria of crime prevention. However, the measures taken have not yet provided a radical solution to the problem of prevention of street crime. Nevertheless, the introduction of new informational and tele communicational technologies and other new methods of prevention into the activity of the internal affairs agencies has greatly benefitted the public order maintenance domain which is now known for its diversity and dynamics. This case requires constant analysis of the current state of affairs in this area, creation of new approaches towards the realization of the assigned task and perfecting the existing forms and methods of work [5$10]$.

Signs of street crime

Criteria, by which crimes, committed in public places are referred to as street crimes are stated in the Instruction of the United Crime Registration as of the 29th of December of 2005. (Orders of the Prosecutor General's Office of the Russian Federation No. 39, Ministry of Internal Affairs No. 1070, Ministry of Emergency Situations of the Russian Federation No. 1021, Ministry of

Justice of the Russian Federation No. 253, Federal Security Service of the Russian Federation

No. 780, Ministry of Economic Development of the Russian Federation No. 353, Federal Drug Control Service of the Russian Federation No. 399 of December 29, 2005) where it's specified that they are "...acts, committed in places with unlimited access during any season and time of day, with an objective need of patrol-post details (according to the plan of "common dislocation"):

-in the streets, squares, prospects, boulevards, seafronts, overpasses, etc. (including bus stops and terminal stops);

- in specifically equipped beaches(except departmental and periodically closing ones( -in markets, stadiums, dancefloors during workhours( except covered malls and periodically closing sports centers, gyms(

-in parks, squares, alleys, dead ends, yards (except for private properties);

- inforest and park areas, on banks of open water sources, in the water and surrounding rest areas and green areas in cities and towns)

The street sphere as a specific part of the spatial distribution of crime is closely linked to the concepts of geography, ecology and topography of crime (Avanesov, 1984).

1. Geography of crimes- a spatial and temporal distribution of penalties (by level, structure, dynamics), associated with the specifics of various world regions, countries or administrative and territorial units within one country; with the population, structure and accommodation of people on the examined territories with specific forms of social organization, work and life conditions, relaxation, culture, national traditions and specifics. (Shnaider,1994) Street crime geography is defined by the city type, in which the public space is located, and city types depend on the regions.

2. Street crime topography allows the study of specific (cartographic) places where street crimes are committed and the perceived safety levels of the population living there. 
Criminal topography focuses on the analyses of crime scenes, which according to the public area definition can take place in squares, parks, beaches and directly in the streets of populated areas. (Zolotuhin, 2000)

3. Aside from the spatial aspect, socio- structural characteristics of public crime scenes

(anonymity, detachment of the population, weak social control, etc.) are considered. (Kivich, 1999) Thus, the ecology of street crime is the organization of peoples' of life and work conditions, relaxation, culture, national traditions and place of residence (street location, structure of located buildings and constructions; characteristics of residing and visiting persons). Thus, topography-is the disposition of the object on the city map, and ecology- the characteristics of such disposition.

Street crime (Lukininih,2009) is part of city crime and as a systemic phenomenon, has its own legitimacy of origin, development and function and is determined by:

-open city space (street space) - a physical feature of the place, depending on the city type

(functions, district planning, streets, etc.) ${ }^{\wedge} 1$, where specific criminogenic factors are formed; -social characteristics of the street domain- is an independent domain of constant interaction which includes relationships of independent and unacquainted people, taking place outside of living or working spaces during their location in the street (public place) [11-14]

\section{Methods of study}

The main applied study methods are: theoretical analysis of the subject of the study using specific literature; logical analysis of the concept contents and signs of street crime; content- analysis of the valid organizational and methodical provision for fighting crime, committed in the streets; content-analysis of statistical, informational, strategic and official, analytical and other practical materials of internal affairs agencies and other subjects of street crime prevention; structural and functional analysis of subject activities towards street crime prevention; methods of sociological studies (surveys, interviews, polls); methods of prediction, factorial analysis, etc.

In particular, the information of the inquiry form on criminal cases for 2006-2016 is reviewed.

I. Information characterizing the crime 1. Place of the crime.

-street $-72.3 \%$

-other places - $27.7 \%$

-outside the populated area of the accident - 14.2\%

-next to the scene $-89.3 \%$

2. Time of crime:

-morning $-7.2 \%$

-day $-15.3 \%$

-evening - $32.3 \%$

-night $-35.3 \%$

-working day - $22.5 \%$

-pre-departure - $25.3 \%$

-pre-holiday - $10.2 \%$

-day off - $31.7 \%$

-day of the national holiday - $8,2 \%$

3. Were there any accomplices:

-yes $-68.3 \%$

-no - $31,7 \%$

4. Way of committing the crime: 
-with firearms (hunting rifle, rifle, automatic, pistol, homemade rifle) - 3,5\%

-with a cold weapon (hunting knife, dagger, dagger), factory-made, self-made $-11.3 \%$

-with a chopping, cutting or stabbing implement (ax, knife, etc.) - $11.0 \%$

- by beating with fists or kicks, strangulation, poisoning, etc. - $43.2 \%$

-other - $31.0 \%$

5. Characteristics of the offender at the time of the crime:

a) the offense is committed:

-in a sober state $-62.3 \%$

-the state of alcoholic (narcotic) intoxication - $37.7 \%$ b) was it intentional:

-it was planned in advance - $38,3 \%$

-the criminal intention arose suddenly $-61.7 \%$

c) if the crime was premeditated, what was the preparation like

d)did the offender expect, at the time of the crime, that:

the victim can resist:

-yes $-77.5 \% \quad-$ no $-22.5 \%$ eyewitnesses will stop his illegal activities:

-no $-59.9 \% \quad$-yes $-40.1 \%$

e)If so, what prompted the continued criminal intent

f) what was the basis for planning the street crime:

-the absence of witnesses- $14.7 \%$;

-the confidence in impunity - 24.3\%;

-other calculation - $13.6 \%$;

-not established - 27.1\%; $\quad$-did not think about it - 20.3\%

g)Motivation for committing a street crime:

-the victim's behavior - $30.9 \%$;

-temporary, momentary material difficulties - $13.2 \%$;

-actions committed in a state of intoxication $-40.4 \%$;

-other motives $-7.4 \%$;

-not established $-8.1 \%$;

6. Characteristics of the victim at the time of the crime:

a) was alone - $91.5 \%$

b)is the victim guilty of the situation:

-yes $-75.2 \%$

-no $-11.8 \%$

-not established - $13.0 \%$

c) What was the fault of the victim:

-imprudence - $23.3 \%$

-alcoholic (narcotic) intoxication - 34.2\%

-provocative behavior - $15.4 \%$

-not established - $27.1 \%$

d)the relationship of the victim with the offender at the time of the crime:

e)-positive $-3.5 \%$

-neutral $-77.2 \%$

-hostile - $19.3 \%$

f) the victim at the time of the incident was:

-in a state of intoxication $-35.0 \%$

-in a sober state $-65,0 \%$

g)the crime was related to the performance of social or civil duties by the victim (police officer, citizen, who tried to stop the violation of public order) $-5.2 \%$

h)what was the purpose of their being at the designated location:

-home $-32.3 \%$

-to work - $18.4 \%$ 
-on business - $27.0 \%$

-by chance $-11.3 \%$

-idle - $12.0 \%$

i) whether the victim has taken security measures while being at the place:

j) - yes $-23.5 \%$

-no $-70.2 \%$

-not established - 6,3\%

$\mathrm{k}$ )whether the victim had a feeling of threat at the time of the criminal assault, including direct threat from the offender:

-yes $-12.3 \%$

-no $-81.1 \% \quad$-established $-6.6 \%$

1) if given another chance, could the victim avoid the conflict (crime) :

- no $-47.2 \%$

-yes $-13.3 \%$

-not established $-39.5 \%$

7. Factors contributing to the committing of a street crime:

What circumstances contributed to the fact that the crime was not prevented (in order of importance):

1 -shortcomings in the function street police patrols and public services

2-failure to respond to incoming signals

3-other circumstances

4-non-interference of bystanders of the crime

5 -absence of due reaction of the public to the unlawful actions of the offender 6 - lack of due supervision of persons with psychological deviations

II. Information characterizing the identity of the victim: a) gender: -male $-74.3 \%$ -female $-25.7 \%$ b) age:

-adult $-89.3 \%$-underage 10.7

c) the familiarity with the offender:

-familiar $18.2 \%$

-unfamiliar - 81.8\%

\section{The results of the study of the criminalisation of the street space}

«Statistics have long played a role in law enforcement, now the masses of crime data collected over the years is being given a new lease of life through big data analytics. If actually accurate, predictive policing can fundamentally change the way law enforcement reacts, or proacts, to illegal and dangerous activities, making our smart cities safer. That is until "smart" criminals start using this data to avoid "smart" police» (The Internet of Law Enforcement In Smart Cities, 2016). Thus, depending on the level of appeal to criminals street crimes have been rated through

- districts with industrial areas (where more than half of the territory is occupied with industrial facilities) $-2,8 \%$

- districts with cultural and administrative facilities (where more than half of the territory is occupied with such buildings) - $8,2 \%$

- districts with high traffic levels(more than half of the territory is occupied with transportrelated facilities( $-11,5 \%$

- districts with shopping malls (more than half of the territory is occupied with shopping facilities) $-24,8 \%$ 
- housing districts with massive daily departure for work to industrial areas and late night return (more than half of the territory is occupied with housing facilities) (Grishin, 1998) - 53,2\%

Aside from that, mixed type city districts can be distinguished:

-cultural-industrial districts with a rather high industrial potential and a developed network of cultural entertainment and shopping facilities, with a high concentration of people, living outside of the city;

-housing-industrial functional and household spheres of life, which are characterized by a high level of pendulum migration of the population.

The analysis of the criminal and administrative legislation allowed us to distinguish the following fixed forms of public order violations:

small violations of public order (expressed through an evident lack of respect towards society

(minor hooliganism(Article 20.1 of the Code of Administrative Offenses of the Russian Federation); drinking beer and drinks made on its basis, alcohol containing products or psychotropic drug and other drug usage in public places (Article 20.20 of the Code of

Administrative Offenses of the Russian Federation); presence in public places while being under alcohol intoxication(Article 20.21 of the Code of Administrative Offenses of the Russian Federation);

an outrage of public order, expressed in evident lack of respect towards society (Articles 213 and 214 of the Criminal Code of the Russian Federation)

crimes linked to violation ofpublic order (hooliganism (Articles 105, 111, 112, 115, 116, 167, 213 and 245 of the Criminal Code of the Russian Federation)).

The following criminologically valuable signs, characterizing the specifics of the city living conditions (street environment conditions) can be distinguished:

a)related to the public, and public behavior in the street:

- a high concentration of citizens in the streets, parks and squares, caused by a high density of the city population. Accumulation of people in the streets increases the ammount of direct contact between them and increases the probability of conflict situations and crime in the city streets; - high mobility of the population: within the city (internal migration), caused by the difference in housing and work, study, family locations; within the agglomeration (inter-district migration); into the city from other villages, cities, regions (interregional migration);

-the high variety in the choice of potential victims among people in the street; saturation of the streets with subjects, belonging to a marginal environment (homeless and neglected teenagers, bums, prostitutes, drug addicts, alcoholics, etc.) which promotes crimes committed against this category of citizens.

b) related to the anonymity of the street space:

-the criminal appears to be one of the passerby in the crowd. Anonymity of social contacts, due to different places of study, work, housing and entertainment of a big variety of unfamiliar people is enforced by the availability of transportation between city districts. The anonymity of the city way of life reinforces the expectation of impunity and low mobility of the police doesn 't allow for prompt neutralisation of the criminogenic situation;

-at the time of the crime taking place, the criminal and the victim aren 't acquainted, or had met in the street, for example while drinking alcoholic beverages;

- a substantial part of all crime is committed evidently, with no reasonable counteraction from bystanders (they are either passive or trying to distance themselves from the crime scene) -psychological closedness is expressed through people not taking notice of their surroundings and their inability to recreate the event that had happened to them. Residents of tall buildings often don't know (and aren 't interested in knowing) their neighbors. That is why victims and bystanders often are unable to recreate the description and appearance of 
the criminal, their weapons and means for committing the crime (about $80 \%$ of citizens are absolutely unable to describe the circumstances of the crime);

c) related to the capacity of social control of the offenders:

-relations in the street space take place in the life processes which are not connected to the work or family life and mostly depend on the specific people entering into such relations. These relations are not structured or formalized;

- lowered in relation to other areas, and in some cases completely absent, necessary social control of public behavior in the streets, with a high lack of official police control; d) related to the city structure:

-the possible usage of the criminogenic properties of the streets by the offender to achieve their criminal goals and quickly escape the crime scene (hide in the crowd, buildings, parks, squares, etc.) ; a developed transportation system also makes it easier for the criminal to escape the crime scene.

Seasonal fluctuations of street crime are most expressed in the analysis of mercenary violent crimes (robberies). The average monthly index of these crimes during the cold seasons amounted to $58 \%$ of crimes. Their dynamic presents in a certain way: from January to April the amount of crimes drops, May-June it appears to be on the same level, and starting from July the number of registered robberies rises until it's peak in OctoberNovember.

One of the reasons for such seasonal fluctuations is the problem of excessive free time. (Grishin, 1998)

A study of the time intervals of various street crimes by the day of the week in 2008 2016 revealed that the evident rise of robberies $(+11.5 \%)$ and violent attacks $(+18.5 \%)$ takes place at the end of the week (Friday, Saturday, Sunday).

Table 1. The structure of crimes, committed in the streets, squares and parks of populated areas in 2008-2018.

\begin{tabular}{|c|c|}
\hline Days of the week & Amount of street crimes (in \%) \\
\hline Friday & 25,3 \\
\hline Saturday & 30,1 \\
\hline Sunday & 24,0 \\
\hline Monday & 4,8 \\
\hline Other work days & 15,8 \\
\hline
\end{tabular}

In recent years, there has been a steady increase in the number of robberies committed in the streets from $10 \mathrm{pm}$ to $6 \mathrm{am}$. Thus, if in 2004-2009 most robberies were committed in the daytime (from $10 \mathrm{am}$ to $6 \mathrm{pm}$ ) and accounted for $44.8 \%$ and $37.4 \%$ of all registered crimes, starting from 2010, a large part of robberies in public places took place at night (from 10pm to 6am): $2011-36.4 \%$; $2013-36.5 \%$; $2016-37.2 \%$.

The time analysis of street robberies during the day indicates that the most dangerous periods for citizens are from $10 \mathrm{pm}$ to $11 \mathrm{pm}$ (respectively, $12.6 \%$ and $18.7 \%$ of crimes) and from 00 am to $1 \mathrm{am}(7.6 \%$ and $22.6 \%$ of crimes).

The prevailing mercenary direction of street crimes today is caused by the possession of accessible objects of encroachment, such as : personal and carried belongings ; means of mobile communication; jewelry; sums of money that are likely used by criminals immediately after the crime.

In the evaluation of criminal encroachments during street robbery mobile phones account for $41.4 \%$, money $-28.1 \%$, clothing and shoes $-21.9 \%$, industrial goods $-14.9 \%$, jewelry $-7.9 \%$, documents $-0,7 \%$.

The relatively high cost of mobile phones, increased demand and ease of realization made them one of the main subjects of criminal assault, and therefore mobile phones were the number one subject of encroachment during the robbery. 
When committing robberies and theft attacks alone, the offender often acts out certain steps such as: attacking from an ambush, tracking down the victim, or luring them into a deserted place. Attacks from the ambush occurs in hidden places, where a person with a large sum of money is expected to pass, for example, on the pay day at the company, payment of pensions, etc., to exclude all possible resistance the offender approaches the intended victim from the back and delivers a blow to their head or throws a loop around their neck.

For disguise criminals use masks, bandages, glasses, change clothes or turn them inside out, cover their head with a hat or raise their collars. Typically, the disguise is applied immediately before the crime (Tselischev, 1986).

When tracking a victim, the offender can appear in pubs, cafes, restaurants, markets, looking for a person with a large amount of money. They then follow the victim until a suitable moment and place come up and then carry out their plan. Sometimes after identifying such a person, they get acquainted with them, treat them with liquor, and then with various reasoning lead them into a secluded place. There are cases when criminals even use prostitutes for this purpose.

In most cases the offender chooses a victim which is incapable of resistance and approaches it under some common reason: asking for a cigarette, the time of day or directions, etc., and then suddenly injures the victim or forces them onto the ground without causing physical harm, but psychologically suppressing and restraining movement, or threatens with violence, and then snatches their belongings.

Ways of committing robberies and thefts associated with mobile phones can be separately dentified. Such asi:

-the phone is snatched from the victim's hands or pockets;

-the phone is ripped off if it is openly hanging on the strap;

-the phone gets knocked out (usually when a person is talking on the phone or in the moment when they take out their mobile phone to answer the call); -the phone is taken away under threats of violence.

Thus, the street has a negative impact on the behavior of the offender - this is called the "urban" factor.

The city provides certain favorable conditions for the offender. They are related to the availability of public transport, places of mass gathering, shopping areas all of which promote the possibility of pocket theft. The high density of the city's population allows criminals to hide in crowds of people without the fear of being exposed and easily sell stolen goods.

The specific "urban" conditions contribute to the "depersonalization" of individuals. Violent robberies and thefts as well as a significant proportion of violent crimes in the city are usually committed against unfamiliar people. "Anonymity" strengthens the sense of impunity and is part of the motivation mechanism of criminal acts. This feeling allows offenders to overcome the uncertainty and stimulates the dedication to especially dangerous forms of violence in order to achieve criminal goals.

Currently, the information on the state of street crime is not taken into account fully (there is no cartographic analysis or tables of crime records by type, time of committing, result). The prevention of street crimes should be aimed at neutralizing the negative conditions of the street factor (Gladkikh, 1996).

In general, the criminological organization of urban space applies the following measures:

Political (administrative) centers in the city should be closed after 7pm;

Entertainment areas should be concentrated in one place within the city;

Night institutions should be opened according to the following rule: one in conjunction with others. Thus, a store that operates 24 hours a day, as a rule, should be part of a large 
network with a developed infrastructure, with a permission to operate from the local administration. In order to reduce the number of people who have to to appear on the streets at night, it is necessary to introduce the home delivery of goods upon request (via the Internet) from night stores, pharmacies and etc.;

All stalls and shopping tents should be closed at nighttime;

Only one night shop should be opened per one housing area;

For persons who return home from late night shifts, large enterprises should organize the transportation of their workers to the house, while medium and small enterprises should create larger public transportation routes;

Taxi delivery should be arranged from late events to the house of persons who had had their cars placed in the parking area beforehand;

Parks and public gardens should be closed during the night, as well as all the surrounding shops.

Similar measures will bring order to nighttime street trade and strengthen compliance with laws in the city.

\section{Conclusions and suggestions}

The results of our research (with the help of the Academy of Management of the Ministry of Internal Affairs of the Russian Federation - 2009-2011, 2015-2017) show that, the existing system of measures for street crime prevention and their practice did not ensure the liquidation of criminals from the streets and therefore needs further development, while also taking into account the increasing possibilities of the Internet space. "Over the past few decades, the technology has begun to play a very important role in our day to day lives. Our internet enabled gadgets have changed the way we work, play or even carry out daily chores." (Cyber Security A necessary pillar of Smart Cities, 2016).

This is why it is believed that the Internet aids in the development of almost all aspects of urban infrastructure and management, i.e. reducing traffic, parking restrictions, environmental pollution, energy consumption and crime (Chambers, 2014).

The archived (statistical) data of the territorial law enforcement facilities will make it easily possible, to paint sections of the city streets different colors depending on the level of crime in the are (the frequency of committing crimes, the time, the places of crime, the type of crime) based on the history of the area. Such an overview of the street space can be compiled for the season and updated periodically (in the online mode) with new data on incidents of the law enforcement facilities.

Why should this idea be implemented?

The introduction this idea will prompt residents and guests of the capital to be more attentive at certain times of day, on a particular day of the month, in the place they are at. By using their digital device to visually, detect the increased danger of becoming a victim of a violent crime, since a particular area of the urban space in the mobile device is painted red or even in a dark-red color. The user, upon receiving such information, either plans their route in advance accordingly, or makes adjustments judging by with the data received from the device. Therefore, individuals can reduce their own crime risks by carrying a mobile telephone and avoiding high-risk situations, for example, somebody who normally travels by public transit may hire a taxi when returning at night from an isolated destination (Litman, 2013).

For law enforcement facilities and local governments that provide public order in the streets, such mobile device data will help plan and develop new measures to prevent street crimes in their area.

The second goal (after informing the residents) is the prevention and suppression of street delinquencies. That is, on the same map there will be icons that allow the user to 
quickly find answers to important questions if they are already in criminal situation (and are a victim of a street attack) i.e. what to do in order to minimize the negative consequences (addresses of the nearest institutions, pharmacies, police departments, etc.), to stop the further activity of the street criminal (phones, addresses, behavioral advice).

\section{References}

1. N. Zotkina, M. Gusarova, A. Kopytova, Advances in Intelligent Systems and Computing 692, 1204-1213 (2018) DOI: 10.1007/978-3-319-70987-1_129

2. A. Kopytova, Procedia Engineering 165, 1132 (2016) DOI: 10.1016/j.proeng.2016.11.830

3. A. Kopytova, MATEC Web of Conferences 106, 08056 (2017) DOI: 10.1051/matecconf/201710608056

4. N. Zotkina, S. Bardasov, M. Gusarova, A. Kopytova, MATEC Web of Conferences 106, 08050 (2017) DOI: 10.1051/matecconf $/ 201710608050$

5. K. Pykhtin, T. Simankina, V. Sharmanov, A. Kopytova, IOP Conference Series: Earth and Environmental Science 90(1), 012065 (2017) DOI: 10.1088/17551315/90/1/012065

6. V. Lezier, M. Gusarova, A. Kopytova, IOP Conference Series: Earth and Environmental Science 90 (1), 012034 (2017) DOI: 10.1088/1755-1315/90/1/012034

7. A. Minnullina, R. Abdrazakov, Advances in Intelligent Systems and Computing 692, 1224-1233 (2018) DOI: 10.1007/978-3-319-70987-1_131

8. A.V. Kopytova, Exchange of intellectual property 3 (XIV), 31-37 (2015)

9. V. Lezier, M. Gusarova, A. Kopytova, IOP Conference Series: Earth and Environmental Science 90 (1), 012069 (2017) DOI: 10.1088/1755-1315/90/1/012069

10. A. Mottaeva, A. Minnullina, IOP Conference Series: Earth and Environmental Science 90 (1), 012123 (2017) DOI: 10.1088/1755-1315/90/1/012123

11. M. Gravit, O. Zybina, A. Vaititckii, A. Kopytova, IOP Conference Series: Earth and Environmental Science 90 (1), 012103 (2017) DOI: 10.1088/1755-1315/90/1/012103

12. N. Zotkina, A. Kopytova, M. Zenkina, O. Zhigunova, MATEC Web of Conferences 106, 08058 (2017) DOI: 10.1051/matecconf/201710608058

13. A. Kopytova, E. Matys, N. Zotkina, I. Reshetnikova, N. Meller, I. Nekrasova, E3S Web of Conferences 33,03053 (2018) DOI: 10.1051/e3sconf/20183303053

14. M. Fedorov, E. Matys, A. Kopytova, E3S Web of Conferences 33, 03054 (2018) DOI: $10.1051 / \mathrm{e} 3$ sconf/20183303054 